outlined database content, basic searching procedures, and interpretation of display formats, and also highlighted special databases and files such as the Eighteenth-Century Short Title Catalog and Archives and Manuscripts. Training packets for each participant included RLG instructional material, a mini-manual and quick reference sheet developed by NYU, and log-on procedures through Telenet. We distributed all account and password information at the time of training.

The majority of questions posed by users of remote databases typically relate to technical aspects of online searching, such as how to connect, download, and print. Our experience with RLIN is no exception. Given the variety of communications software packages available, we did not attempt to give RAP users a crash course in telecommunications. Rather, we provided assistance for packages used on campus, such as ProComm and Kermit and, where appropriate, referred users to the RLIN Information Center or their user manuals. In addition, as previously mentioned, we provided packets that contained detailed instructions on Telenet access and a Telenet help number.

The RLIN/RAP training sessions were an excellent opportunity for librarians to learn more about faculty research and for faculty to increase their awareness of library initiatives in the areas of database design and resource sharing. Further explanation of the MARC record structure was of special interest to several faculty involved in database construction, and created a common basis for understanding indexing and retrieval. The training sessions also gave us the opportunity to stress the utility of using NYU's online catalog, BobCat, in conjunction with RLIN for identifying local resources.

One of RLIN's strengths, of course, is the display of holdings information for member libraries. The breadth of the database and inclusion of location information within each record combine to create a powerful verification tool for faculty searchers. Because so many libraries within the metropolitan area contribute to the RLIN database, NYU faculty are able to identify a tremendous amount of locally available material from libraries such as Columbia, New York Public, the Metropolitan Museum, and a host of similar institutions.

Searching RLIN for themselves, faculty are introduced to the vast potential and importance of RLG's resource sharing programs.

An evaluation instrument, along with information collected by RLG, will provide extensive data on the relative ease or difficulty of searching the database, the usefulness of various files and special databases, and what barriers, if any, exist for end user access to RLIN. In addition, it will indicate impact on interlibrary loan, on-site referrals, and collection development activities, such as book purchase recommendations. Since the program has evolved differently among the RAP institutions, of interest will be the effect of various training approaches, attitudes toward the cost of searching, and satisfaction with the database. We will administer evaluations as participants complete their initial ten hours of connect time.

After only a few months, participants have expressed enthusiasm about using RLIN, due to its comprehensiveness as a database and its usefulness as a verification and location tool. As growing numbers of NYU faculty tap into RLIN, we are assessing our interlibrary loan program, considering document delivery options, and furthering our knowledge of the scholarly communication process. The Research Access Project is one of many initiatives in remote delivery of library services enabling us to realize the full potential of electronic access to information.

\title{
When closing a library is progress
}

\author{
By Rebecca Sturm \\ Head of Public Services \\ Northern Kentucky University
}

Like many other medium-sized academic libraries at the start of this decade, our university got caught up in the need to establish another campus, complete with a small library facility. Located in Covington, which was the original site of the University and about fifteen minutes from its present location, University College was established with a dean in the spring of 1983. The campus offers a variety of courses and special offerings and services, but no distinct academic programs. Faced with little start up money, slim hope of additional funds in the future and "no thank you" not an option, against our best instincts the library during the academic year of 1983-1984 set up what was called a "library referral center" for the new University College.

The Library Referral Center (afterwards referred to as the UCLRC) consisted of a small gen- 
eral cataloged book collection, some subscriptions to magazines and newspapers, reserve readings, telephone access to the main library and staffing by student employees for about 20 hours per week. The facility closed between semesters and during holidays and the summer, when course offerings were minimal or nonexistent. Although we'd been willing to send books from Highland Heights to Covington, our card catalog was not online, access and verification was unwieldy and so requests for this service were few.

By 1987, still no distinct programs had emerged on the "other" campus, budgets had not increased for the library, and despite trying a variety of service hours for the UCLRC, use remained slight. This was understandable for many reasons: library hours were limited, students tended to come to that campus for scheduled classes only, not all classes required use of the library or had required reserve readings, students used other closer to home libraries or the main library and the UCLRC collection was itself severely limited in size and scope. Realizing that there were problems to solve, my sabbatical in the fall of 1987 was spent studying the needs for library services of University College and our other off-site situations.

With the current push now to offer courses at a variety of locations in an eight-county service area for the growing "non-traditional" student population and the accompanying need for library support for these courses, the question to be answered is: "Given limited funds, how can we best serve the library needs of students and faculty at these remote sites?" I think the answer lies in not only not establishing additional libraries, but in the removal of inefficient facilities and the establishment of new arrangements, with the result being better library services for all non-main campus locations. Such a decision was made in the spring of 1988 , based on study and discussion during the previous fall and first part of the new year. The current UCLRC will naturally close at the end of the spring semester and then off-site services will emerge in their new forms for the fall semester.

Here's how better library service can result from closing a library facility. Our library was spending approximately $\$ 2,500$ a year for subscriptions and for student employee salaries at the UCLRC. Aside from the initial outlay of staff time and cost to cata$\log$ a small collection, we were only adding random titles, usually gifts or duplicates, to this collection. Other continuing costs for the library in addition to cataloging, such as utilities, telephone, mail and so forth, are not included in the above fig-

${ }^{1}$ There are numerous articles in the library and education literature of the last ten years regarding service for off-site courses, which I will not cite here. ACRL does have Guidelines for Extended Library Services, (C\&RL News, March 1982) and the proceedings of the "Off-Campus Library Services Conferences," available from Central Michigan University Press, are most useful. ures. But even the small sum of $\$ 2,500$ could be better justified if it could be used towards a larger service population than just that of University College.

Our library is an active member of the Greater Cincinnati Library Consortium and various state networks, and as such is on excellent terms with the area and regional public libraries. We are making arrangements for reserve readings for University College or other off-site courses to be placed at appropriate local libraries, such as publics. NKU will pay for photocopying or book purchasing and the public libraries will in turn be extending services to their own populations. Advantages to students will be several: more library hours to choose from, a much larger collection of books, magazines and other informational materials, and a "real" library that they already know how to use or would benefit from learning to use. (We will continue to provide library instruction in a variety of sites as appropriate.)

In addition to the photocopying and book buying mentioned above, the Library will retain the funds from canceled subscriptions and use them to send books and copies of articles to other locations, and the recouped student help will provide for material retrieval, packaging, etc. We now have a telefacsimile machine, and with the decrease in the cost of these machines, we hope to encourage cooperating public libraries to purchase them as well. Local industries may be good candidates for helping to fund such a purchase; companies generally have vested interests in college courses for current or potential employees, purchase of the "fax" for the local public library would benefit the entire community (it could be used for a multitude of tasks aside from the courses) and it would be excellent PR for that industry or business. The University, in turn, could perhaps assist the public libraries in paying for paper and other continuing costs associated with this technology.

I believe that closing a small, seldom-used library facility (that still has fixed costs to maintain) and transferring services to a public library five minutes away will benefit our users. The dean of University College was most supportive of the decision, agreeing with us that the prime concern of most students was where they could obtain needed materials easily and conveniently. Instead of the UCLRC, we will maintain a study area near the old location with dictionaries and encyclopedias, book bags and request forms for books and articles. Other books from the UCLRC (many of which were duplicates) will be removed from our holdings as the cataloging department has time; a small portion of desirable volumes will be added to the main collection. The lobby area (just outside of the former UCLRC location) will have a free campus telephone and a directory for aiding in questions or requests for the main library. When our card catalog goes online, a terminal will also be placed in the current study area. Funds retrieved from closing 
the UCLRC will be used to support the nearby public libraries in serving UC students as well as in supporting course offerings and public libraries at our other off-site locations.

One of our reference faculty has recently agreed to serve as the coordinator of off-site services. His role (as part of his other reference responsibilities) will be to work in conjunction with the director of off-site credit courses and serve as liaison between faculty teaching these courses and our various library departments, such as reserve, interlibrary loan, and library instruction. Consequently, students or faculty from these courses will have to interact with one individual and not the confusing variety of library departments. We hope to in- crease the funding for this coordinator position as need for support for these off-site courses manifests itself.

If one subscribes to the theory of "survival of the fittest," then the initially unpopular but obvious answer is to close a weak and ineffective facility and strengthen and support one nearby, in this case a public library. The best interests of our off-site users demand investigating and implementing such decisions. And like evolution, such closings will not be accomplished overnight, but will involve the slow, often painful process, through research, discussion and negotiation, of changing from one form of library service delivery to other, more sophisticated and appropriate ones.

\title{
Citation forms for bibliographies
}

\section{appearing in journals or as}

\section{component parts of larger works}

\author{
Prepared by the RBMS Standards Committee
}

John B. Thomas, Chair, 1987-88

\section{Updating the "Standard Citation Forms."}

\begin{abstract}
$\mathbf{U}$ sers of Standard Citation Forms for Published Bibliographies and Catalogs Used in Rare Book Cataloging (Washington: Library of Congress, 1982) have noted that its "Working Principles" do not provide specific examples of citation forms for bibliographies published in journals or as component parts of larger works. The Standards Committee of ACRL's Rare Books and Manuscripts Section, after consultation with the editors of Standard Citation Forms, Peter VanWingen and Stephen Paul Davis, recommends that citation forms for such bibliographies be constructed ac-
\end{abstract}

cording to the guidelines given in Section IV of the "Working Principles."

Additional information required to identify the journal or larger work in which a particular bibliography appears should follow the general style recommended by the University of Chicago Press in The Chicago Manual of Style (13th ed., Chicago: University of Chicago Press, 1982, or latest edition). Notice, however, that citation forms do not conform exactly to forms suggested by the University of Chicago Press, e.g., titles are not italicized and imprint information is omitted. Inclusive 